\title{
Close approaches by vessels elicit surface active behaviors by southern resident killer whales
}

\author{
D. P. Noren ${ }^{1, *}$, A. H. Johnson ${ }^{2}$, D. Rehder ${ }^{3}$, A. Larson ${ }^{1}$ \\ ${ }^{1}$ Marine Mammal Program, National Oceanic and Atmospheric Administration, National Marine Fisheries Service, \\ Northwest Fisheries Science Center, 2725 Montlake Blvd. East, Seattle, Washington 98112, USA \\ ${ }^{2}$ University of Washington Bothell, 18115 Campus Way NE, Bothell, Washington 98011, USA \\ ${ }^{3}$ Department of Biology and Wildlife, 211 Irving 1, University of Alaska Fairbanks, Fairbanks, Alaska 99775, USA
}

\begin{abstract}
Vessel disturbance is one potential risk factor to the endangered population of southern resident killer whales Orcinus orca. This study was conducted to determine if southern resident killer whales perform surface active behaviors (SABs) in response to close approaches by vessels. Data were collected in the San Juan Islands, USA, and Gulf Islands, Canada, from May through September 2005 and 2006. Continuous behavioral data, including the performance of SABs (e.g. spy hops, breaches, tail slaps, pectoral fin slaps), were recorded from southern resident killer whales using a focal follow approach. Distances between the focal whale and nearby vessels were systematically measured throughout each focal follow. In addition, the distance between the nearest vessel and the focal whale was recorded each time the whale performed an SAB. Tail slaps were the most frequently performed SAB. The highest frequency of SABs occurred when the nearest vessel was within 75 to $99 \mathrm{~m}$ and 125 to $149 \mathrm{~m}$ of the focal whale in 2005 and 2006, respectively. Approximately $70 \%$ of SABs occurred when the closest vessel was within $224 \mathrm{~m}$ of the whale. Furthermore, a significantly greater proportion of SABs occurred when vessels closely approached whales. Finally, there was a significant temporal relationship between close approaches and the occurrence of SABs; most SABs were performed near the time of the closest approach by a vessel. These results suggest that close approaches by vessels elicit behavioral responses in southern resident killer whales and that the minimum approach distance of $100 \mathrm{~m}$ in whale-watching guidelines may be insufficient in preventing behavioral responses from whales.
\end{abstract}

KEY WORDS: Behavior · Boat · Cetacean · Disturbance $\cdot$ Guidelines $\cdot$ Killer whale $\cdot$ Orcinus orca Resale or republication not permitted without written consent of the publisher

\section{INTRODUCTION}

Whale-watching has become increasingly popular over the last 2 decades. Since many targeted species are classified as endangered or threatened, the whalewatching industry is also a potential medium for addressing conservation issues through experiential educational opportunities (Orams 2000, Luck 2003, Corkeron 2004). However, while there are many benefits associated with whale-watching, increased boat traffic and noise levels may affect marine mammals by increasing physiological indicators of stress (Romano et al. 2004), increasing daily energetic costs (Williams et al. 2006) and/or inhibiting important behaviors nec- essary for survival (Williams et al. 2006, Hodgson \& Marsh 2007, Lusseau et al. 2009).

Southern resident killer whales Orcinus orca are piscivorous whales that spend the majority of the summer months (May to September) in the US San Juan Islands and neighboring Canadian Gulf islands (Bigg 1982, Krahn et al. 2002). The whales' predictable presence makes the islands an ideal location for commercial whale-watching enterprises and private recreational whale-watching. Vessel-based whale-watching in the San Juan Islands has increased significantly since the late 1980s for both private and commercial boats (Duffus \& Baird 1995). For example, the number of vessels in the commercial whale-watch fleet in- 
creased from approximately 10 in 1985 to nearly 80 in 1997 (Koski 2004). In recent years (2000 to 2006), the number of vessels in the fleet has remained fairly stable at approximately 75 (Koski 2007). Moreover, from 1998 to 2006, southern resident killer whales consistently had an average of nearly 20 vessels (private, commercial, kayak, research, etc.) within a half-mile of their location between 09:00 and 18:00 h from May through September (Koski 2007). For this same time frame, maximum boat counts within a half-mile of the whales ranged from 69 to 120 vessels (Koski 2007).

Increased vessel activity near southern resident killer whales is a concern because this distinct population segment (DPS) experienced a $20 \%$ population decline from 1996 to 2001 (Krahn et al. 2002). The precipitous decline from 97 to 78 individuals in this small DPS resulted in a 'depleted' listing under the US Marine Mammal Protection Act (MMPA) and 'endangered' listings under the US Endangered Species Act (ESA) and the Canadian Species at Risk Act (SARA). Because a large number of vessels are often in the immediate vicinity of these whales during the summer months, vessel disturbance was identified as one of the potential risk factors associated with their decline (Krahn et al. 2002). Other risk factors include reduced prey availability and quality as well as high levels of persistent contaminants (Krahn et al. 2002).

It is evident that southern resident killer whales are exposed to multiple vessels daily during their residence in the San Juan Island region. This is a concern because vessel presence may elicit long- and shortterm behavioral changes in delphinids. These include: decreased use of primary habitats (Allen \& Read 2000, Lusseau 2005), altered spatial distribution among individuals (Au \& Perryman 1982, Bejder et al. 1999, 2006, Nowacek et al. 2001, Jelinski et al. 2002), altered behavioral budgets (Chilvers et al. 2003, Coscarella et al. 2003, Lusseau 2003a, 2004, Constantine et al. 2004, King \& Heinen 2004, Lemon et al. 2006, Williams et al. 2006, Hodgson \& Marsh 2007, Lusseau et al. 2009), changed swimming speed or direction (Au \& Perryman 1982, Kruse 1991, Au \& Green 2000, Nowacek et al. 2001, Williams et al. 2002a,b, Jahoda et al. 2003, Lusseau 2003b, Ng \& Leung 2003, Bejder et al. 2006, Lemon et al. 2006, Williams \& Ashe 2007) and altered surface and dive durations (Janik \& Thompson 1996, $\mathrm{Au} \&$ Green 2000, Jahoda et al. 2003, Lusseau 2003a, b, $\mathrm{Ng} \&$ Leung 2003). Surface active behaviors (SABs), such as tail slaps, pectoral fin slaps, leaps and jumps, may also be displayed in response to approaching vessels (Weinrich et al. 2001, Williams et al. 2002a, Coscarella et al. 2003, Danil et al. 2005, Lusseau 2006a).

Though previous studies on southern resident killer whales have shown that vessel presence can have acoustic (Erbe 2002, Foote et al. 2004, Holt et al. 2009) and behavioral impacts (Lusseau et al. 2009, Williams et al. 2009), it is also important to determine whether these whales perform SABs in response to approaching vessels. This is because the performance of these behaviors can be energetically costly (Yazdi et al. 1999), and energetic impacts are of particular concern for these killer whales, which may be food limited (Ford et al. 2005).

The present study aimed to determine whether endangered southern resident killer whales display SABs when closely approached by vessels. Specifically, whale and vessel behaviors were recorded to assess the relationships between vessel distance and mode of operation and the performance of SABs by southern resident killer whales.

\section{MATERIALS AND METHODS}

Study area. Research was conducted in nearshore waters off the San Juan Islands, USA, and off the east coast of Vancouver Island and the southern Gulf Islands, Canada (approximate range of study area: $48^{\circ} 15^{\prime} \mathrm{N}$ to $49^{\circ} \mathrm{N}, 122^{\circ} 35^{\prime} \mathrm{W}$ to $123^{\circ} 30^{\prime} \mathrm{W}$ ), from early June through mid-September 2005 and mid-May through early August 2006. Data were collected only in Beaufort sea states $\leq 3$, between 07:00 and 18:00 $\mathrm{h}$ and while visibility conditions were adequate for locating and following killer whales. Southern resident killer whales were located each day by searching areas they frequent and by monitoring the VHF radio channel and pager system used by commercial whale-watchers.

Behavioral data. Behavioral data from individually identified southern resident killer whales were collected continuously using a focal follow approach. Data were collected from a research vessel $(7.9 \mathrm{~m}$ aluminum boat with a $225 \mathrm{hp} \mathrm{4}$-stroke outboard motor) that was operated according to strict adherence to voluntary guidelines for watching southern resident killer whales (http://www.bewhalewise.org/bewhalewise. pdf). Specifically, the research vessel slowly approached each focal killer whale from behind and parallel to the whale's swimming path. Data were collected while the vessel traveled at a slow speed in parallel with the focal whale at a distance $\geq 100 \mathrm{~m}$. These procedures are identical to those followed by commercial whale-watch operators in the region, although the research vessel usually paralleled whales at distances that were well beyond $100 \mathrm{~m}$. The average $( \pm \mathrm{SE})$ operating distance between the research vessel and focal whale was $199.8 \pm 6.0 \mathrm{~m}$ in 2005 and $224.5 \pm$ $4.4 \mathrm{~m}$ in 2006 . These operating distances were somewhat dictated by the behavior of other boats in the area, and the increase in operating distance between 
the 2 years was due to a difference in the mode of whale-watch vessel operation between the 2 years. Specifically, there was an increased presence of enforcement officials on the water, and the guidelines also changed in 2006. Dissimilar to guidelines in 2005, those in 2006 stated that vessel operators were to move their vessels away from oncoming whales in order to minimize the likelihood that vessels would ever be within $100 \mathrm{~m}$ of whales, even if the whales approached the vessels. It is important to note, though, that in practice, the research vessel followed the 2006 guidelines during both years in order to perpetually maintain a distance of $>100 \mathrm{~m}$ from focal whales during data collection.

Data from a single southern resident killer whale, readily identified by unique markings on its dorsal fin and the grey saddle patch at the base of the dorsal fin (van Ginneken et al. 2005, Ellifrit et al. 2006), were recorded during each focal follow. A previous study on the effects of vessel presence on southern resident killer whales (Williams et al. 2009) found that the performance of SAB bouts was not influenced by sex or age but that younger animals tended to perform more individual SABs within bouts. Thus, for the present study, focal follows were only conducted on older animals to minimize the variability in responses due to age. With the exception of one focal follow of a $10 \mathrm{yr}$ old male in 2005, data were only collected from adult females and adolescent and adult males. Otherwise, focal animals were selected in the field at random, with an overall goal to collect data from several different individuals from all 3 pods. However, accessibility to whales did depend on the locations of other whales, boats and land.

The time of occurrence for every SAB (defined in Table 1) performed by the focal whale was recorded on a handheld PDA (Palm IIIxe, Palm) using Event 3.0 Software (program designed by J. Ha, Department of Psychology, University of Washington). Occurrences of every dive initiation, dive termination and respiration, as well as swimming speed were concurrently recorded on the same handheld PDA (these results will be presented elsewhere). Data (number of whales, pod identification, activity state, directionality, configuration and spatial arrangement) from the group of killer whales that the focal animal associated with were also collected every $10 \mathrm{~min}$ via instantaneous scan sampling from a second handheld PDA during focal fol-

Table 1. Orcinus orca. Definition of surface active behaviors performed by southern resident killer whales

\begin{tabular}{|c|c|}
\hline Surface active behavior & Description \\
\hline Breach & $\begin{array}{l}\text { The body of the whale clears the water completely and then lands on the lateral or ventral } \\
\text { side, generating a large splash. }\end{array}$ \\
\hline Cartwheel & $\begin{array}{l}\text { The whale performs an exaggerated tail slap by hurling the posterior portion of the body, } \\
\text { from the dorsal fin to the tail, out of the water and over its head. The entire posterior end } \\
\text { of the whale (dorsal, lateral or ventral side up) lands, generating a large splash. }\end{array}$ \\
\hline Dorsal slap & $\begin{array}{l}\text { The whale slaps the water with its dorsal fin by rolling onto its side with force, generating } \\
\text { a splash. }\end{array}$ \\
\hline Half breach & $\begin{array}{l}\text { One half to two-thirds of the anterior portion of the whale clears the water and then lands } \\
\text { on the lateral or ventral side, generating a large splash. }\end{array}$ \\
\hline Pectoral fin slap & The whale slaps one or both pectoral fins (ventral or lateral side up), generating a splash. \\
\hline Spyhop & $\begin{array}{l}\text { The whale rises vertically out of the water so that both eyes are exposed. The pectoral fins } \\
\text { can either be in or out of the water. }\end{array}$ \\
\hline Tail slap & $\begin{array}{l}\text { The whale slaps its tail (dorsal or ventral side up) on the surface of the water, generating } \\
\text { a splash. }\end{array}$ \\
\hline
\end{tabular}

Table 2. Orcinus orca. Definition of activity states observed in southern resident killer whales based on Ford (1989)

\begin{tabular}{|c|c|}
\hline Activity state & Description \\
\hline Forage & $\begin{array}{l}\text { Searching and/or locating food indicated by arch dives, non-directional swimming and } \\
\text { lunges at the surface. Often includes long duration dives. }\end{array}$ \\
\hline Rest & $\begin{array}{l}\text { Swimming at speeds of less than } 2 \text { knots or completely stationary with respiratory } \\
\text { synchrony and tight spatial associations among whales. }\end{array}$ \\
\hline Social & $\begin{array}{l}\text { Interacting with other members of the pod, members of other pods or with inanimate objects. } \\
\text { Can include sexual and surface active behaviors. }\end{array}$ \\
\hline Travel & Directional movement at a steady pace, often with coordination of the entire group. \\
\hline
\end{tabular}


lows. The data on activity state (Table 2, based on Ford 1989) were used to determine if SABs occurred preferentially during particular states. Focal follows were terminated whenever a surfacing event was missed by the observer, other vessels obstructed observations or after approximately $40 \mathrm{~min}$ of continuous data collection.

To minimize pseudoreplication and further eliminate the bias of age on the rate of SABs (Williams et al. 2009), SAB bouts, rather than every individual SAB, were included in the analysis. We defined an SAB bout as a series of one or more SABs performed sequentially with $\leq 1$ min lapsing between the execution of each successive behavior. We deemed this to be a robust approach because $67 \%$ of SABs were performed within $\leq 1 \mathrm{~min}$ of the preceding $\mathrm{SAB}$ when multiple SABs were performed during a focal follow. For the remaining $33 \%$ of these cases, individual SABs were separated in time by $65 \mathrm{sec}$ to $25 \mathrm{~min}$, with over $50 \%$ of these separated by $\geq 5$ min.

Vessel data. Distances between the research vessel and the focal whale and between the research vessel and the 2 vessels closest to the focal whale (identified as commercial, private, kayak, research or unknown) were measured using a laser range finder (Yardage Pro 1000, Bushnell) at least every 10 min in 2005 and every $5 \mathrm{~min}$ in 2006. Schematic drawings, indicating positions, distances, and estimated angles (in $5^{\circ}$ increments), were also made for each set of measurements. Additionally, in 2006 these measurements and drawings were made and the behavior (idling stationary, shut-down stationary or moving under motor) of the vessels were recorded every time the focal whale performed an SAB. Although distances were not always recorded when focal whales performed SABs in 2005, a sufficient sample of distances measured during SABs existed in the data set to warrant inclusion in the analysis.

The schematic drawings were used to determine the distance of the closest vessel to the focal whale for each set of measurements taken. The distance between the focal whale and the closest vessel was calculated using simple subtraction and addition when the placement of the focal whale and the vessels was linear, and trigonometrically when the vessels and the whale were in a triangular configuration. Similar calculation methods were used by Suryan \& Harvey (1999).

Distances for the point of closest approach (POCA) by a vessel during each focal follow and for the nearest vessel during each $\mathrm{SAB}$ bout were included in the analysis. The POCA for each focal follow was defined as the shortest distance between any vessel and the focal whale recorded during the entire focal follow. The distance of the nearest vessel during an SAB bout was defined as the distance between the focal whale and the closest vessel when the first SAB within the bout occurred. Distances between the research vessel and focal killer whales were included in all analyses because the research vessel followed killer whales in a manner similar to private and commercial whalewatch boats and was thus considered to be part of the collective whale-watching fleet.

Finally, because the commercial and private boats found in the study area were so numerous and diverse, it was not possible to assess whether specific vessel or motor types were more likely to elicit behavioral responses from killer whales. For example, there were 74 and 76 active commercial whale-watch vessels from 39 and 41 companies in 2005 (Koski 2006) and 2006 (Koski 2007), respectively.

Data analysis. The small size of the southern resident killer whale DPS precluded the selection of only one focal follow per individual for the analysis. However, we presumed each focal follow was an independent sample because data were collected from individuals at different time periods during the day, on different days spanning several months over 2 yr and across a wide range of vessel traffic conditions. Data from males and females were pooled because Williams et al. (2009) found no sex-specific differences in the performance or rate of SABs in southern resident killer whales.

Because of the previously described differences in data collection and whale-watch vessel operation between the 2 years, Kolmogorov-Smirnov 2-sample tests were first used to compare the distributions of data (POCA distances, nearest vessel during SAB distances, temporal differences between the POCA and SABs, etc.) collected in 2005 and 2006. Data were only combined if the distributions did not differ significantly.

The Shapiro-Wilks test was used to determine whether distance data were normally distributed. Because the data were not normally distributed, Mann-Whitney rank sum tests and Kruskal-Wallis 1way ANOVAs on ranks were used to determine significant differences between POCA distances. Kolmogorov-Smirnov tests were also used to compare distributions of data to defined distributions. Parameters in some distributions were estimated using the maximum likelihood method. Chi-squared tests were used to compare the proportion of SAB bouts performed when POCA distances were 'close' and 'far'. Fisher's exact tests were used to compare the number of SABs performed in a bout relative to vessel operation mode. All means are presented \pm 1 SE. Results were significant at $\mathrm{p}<0.05$. All graphical and statistical analyses were conducted using SigmaPlot 11.0, SYSTAT 12.0 and SigmaStat 3.5 Software (SYSTAT Software). 


\section{RESULTS}

\section{Killer whale behavior}

Data were collected from southern resident killer whales during 39 and 37 d on the water in 2005 and 2006, respectively. This effort resulted in a total of 174 focal follows of 36 individual killer whales (72\% of all adults in the population) in 2005 and 193 focal fol- lows of 30 individual killer whales (56\% of all adults in the population) in 2006 (Table 3). On average, 5 focal follows of individual southern resident killer whales were conducted per day (2005: $4.5 \pm 0.4$ focal follows $d^{-1}$; 2006: $5.2 \pm 0.4$ focal follows $d^{-1}$ ). Data were collected continuously during focal follows for an average duration of $17.2 \pm 0.9 \mathrm{~min}$ in 2005 and $20.1 \pm$ $0.8 \mathrm{~min}$ in 2006 , totaling 49.9 and $64.8 \mathrm{~h}$ of data collected, respectively.

Table 3. Orcinus orca. Summary of focal follows conducted on southern resident killer whales that did (with) and did not (without) include the performance of surface active behaviors (SABs). Individual whales are identified by a letter and a number. The letter $(\mathrm{J}, \mathrm{K}$, or $\mathrm{L})$ designates the pod of which the individual is a member

\begin{tabular}{|c|c|c|c|c|c|c|c|}
\hline \multirow[t]{2}{*}{ ID } & \multirow[t]{2}{*}{ Birth year } & \multicolumn{3}{|c|}{2005 focal follows } & \multirow[b]{2}{*}{ With SABs } & \multirow{2}{*}{$\begin{array}{l}2006 \text { focal follows } \\
\text { Without SABs }\end{array}$} & \multirow[b]{2}{*}{ Total } \\
\hline & & With SABs & Without SABs & Total & & & \\
\hline \multicolumn{8}{|c|}{ Females } \\
\hline J002 & 1911 & 2 & 7 & 9 & 5 & 11 & 16 \\
\hline J008 & 1933 & 2 & 0 & 2 & 2 & 2 & 4 \\
\hline J011 & 1972 & 0 & 4 & 4 & 2 & 1 & 3 \\
\hline J014 & 1974 & 1 & 0 & 1 & 0 & 2 & 2 \\
\hline J016 & 1972 & 0 & 2 & 2 & 0 & 1 & 1 \\
\hline J017 & 1977 & 0 & 3 & 3 & 3 & 2 & 5 \\
\hline J019 & 1979 & 0 & 1 & 1 & 1 & 3 & 4 \\
\hline J022 & 1985 & 1 & 3 & 4 & 0 & 0 & 0 \\
\hline J028 & 1993 & 0 & 2 & 2 & 0 & 4 & 4 \\
\hline K007 & 1910 & 1 & 4 & 5 & 2 & 13 & 15 \\
\hline К011 & 1933 & 0 & 5 & 5 & 1 & 6 & 7 \\
\hline К012 & 1972 & 0 & 3 & 3 & 1 & 0 & 1 \\
\hline K013 & 1972 & 0 & 1 & 1 & 0 & 0 & 0 \\
\hline K014 & 1977 & 0 & 0 & 0 & 0 & 2 & 2 \\
\hline K016 & 1985 & 0 & 1 & 1 & 0 & 0 & 0 \\
\hline K020 & 1986 & 1 & 1 & 2 & 0 & 4 & 4 \\
\hline K022 & 1987 & 1 & 4 & 5 & 0 & 2 & 2 \\
\hline K040 & 1963 & 1 & 6 & 7 & 2 & 5 & 7 \\
\hline L002 & 1960 & 0 & 1 & 1 & 0 & 0 & 0 \\
\hline L007 & 1961 & 1 & 0 & 1 & 0 & 0 & 0 \\
\hline L012 & 1933 & 1 & 0 & 1 & 0 & 3 & 3 \\
\hline L022 & 1971 & 2 & 3 & 5 & 0 & 0 & 0 \\
\hline L025 & 1928 & 1 & 3 & 4 & 2 & 0 & 2 \\
\hline L026 & 1956 & 0 & 0 & 0 & 0 & 1 & 1 \\
\hline L043 & 1972 & 0 & 1 & 1 & 0 & 0 & 0 \\
\hline L054 & 1977 & 0 & 1 & 1 & 0 & 0 & 0 \\
\hline L067 & 1985 & 0 & 2 & 2 & 0 & 0 & 0 \\
\hline L072 & 1986 & 0 & 0 & 0 & 0 & 1 & 1 \\
\hline L077 & 1987 & 1 & 3 & 4 & 0 & 0 & 0 \\
\hline \multicolumn{8}{|l|}{ Males } \\
\hline J001 & 1951 & 5 & 24 & 29 & 9 & 22 & 31 \\
\hline J026 & 1991 & 1 & 2 & 3 & 2 & 13 & 15 \\
\hline J027 & 1991 & 0 & 0 & 0 & 2 & 12 & 14 \\
\hline J030 & 1995 & 1 & 0 & 1 & 0 & 0 & 0 \\
\hline K021 & 1986 & 2 & 14 & 16 & 3 & 12 & 15 \\
\hline K026 & 1993 & 0 & 0 & 0 & 2 & 9 & 11 \\
\hline L041 & 1977 & 4 & 9 & 13 & 0 & 8 & 8 \\
\hline L057 & 1977 & 0 & 7 & 7 & 0 & 6 & 6 \\
\hline L071 & 1986 & 0 & 2 & 2 & 0 & 0 & 0 \\
\hline L073 & 1986 & 0 & 0 & 0 & 0 & 2 & 2 \\
\hline L074 & 1986 & 0 & 2 & 2 & 0 & 0 & 0 \\
\hline L078 & 1989 & 1 & 6 & 7 & 0 & 0 & 0 \\
\hline L079 & 1989 & 0 & 17 & 17 & 2 & 2 & 4 \\
\hline L085 & 1991 & 0 & 0 & 0 & 0 & 2 & 2 \\
\hline L087 & 1992 & 0 & 0 & 0 & 0 & 1 & 1 \\
\hline
\end{tabular}


SABs were performed by both male and female killer whales and occurred during 17.2 and $21.2 \%$ of focal follows in 2005 and 2006, respectively (Table 3). For both years combined, SABs were performed during $15.4 \%$ of focal follows conducted on males and $20.0 \%$ of those conducted on females (Table 3). When SABs did occur, a variety of 7 distinct behavior types (see Table 1) were performed in bouts lasting 1 to $78 \mathrm{sec}$ in duration and consisting of 1 to 9 behaviors executed within 1 to $60 \mathrm{sec}$ of the preceding behavior. Tail slaps were the most frequently performed behavior, representing $66 \%$ of the total number of SABs observed in both 2005 and 2006 (Table 4).

Focal killer whales performed SABs during all activity states (rest, forage, travel and social) in 2005 and during travel and forage in 2006. Because the activity state data were primarily collected for another study in 2005 (Marsh 2008), these data did not always temporally match the data collected for the present study. Thus, additional analyses on relationships between the performance of SABs during specific activity states were not possible for data collected in 2005. The data collected in 2006 suggest that SABs were not preferentially performed during particular activity states. Specifically, $71 \%$ of all SAB bouts were performed during travel, which represented $70 \%$ of all activity state observations in 2006. Similarly, $29 \%$ of all SAB bouts were performed during forage, and this activity represented $21 \%$ of all activity state observations. Unlike in 2005, no SAB bouts were performed by focal whales during rest $(7 \%$ of observations) and social ( $2 \%$ of observations) activity states in 2006; however, SABs were performed by other nonfocal individuals during these activity states. Lack of observations of focal whales performing SABs during rest and social activity states is likely an artifact of the rare occurrence of these activity states, rather than an indication that killer whales do not perform SABs during these states. This supposition is particularly supported for the case of socializing whales, which often perform SABs (Ford 1989, see Table 2).

\section{Distance between vessels and killer whales}

The distribution of POCA distances differed significantly between the 2 years (Kolmogorov-Smirnov
[K-S] test, $D=0.190, \mathrm{p}=0.004)$. In addition, POCA distances for all vessel types combined in 2005 (median = $92 \mathrm{~m}$, mean $=111.1 \pm 7.4 \mathrm{~m}$ ) were significantly closer (Mann-Whitney, $T=28695.5, \mathrm{p}=0.001$ ) than those in $2006($ median $=114 \mathrm{~m}$, mean $=131.7 \pm 6.5 \mathrm{~m})$. However, data collection protocols were identical for both years. Thus, POCA distances for the research vessel alone did not differ significantly $(T=13272, \mathrm{p}=0.072)$ between 2005 (median $=117 \mathrm{~m}$, mean $=146.1 \pm 9.1 \mathrm{~m})$ and 2006 (median $=131 \mathrm{~m}$, mean $=156.9 \pm 8.0 \mathrm{~m}$ ) (Fig. 1). In contrast, for all other vessel types combined, excluding the research vessel, the increase in POCA

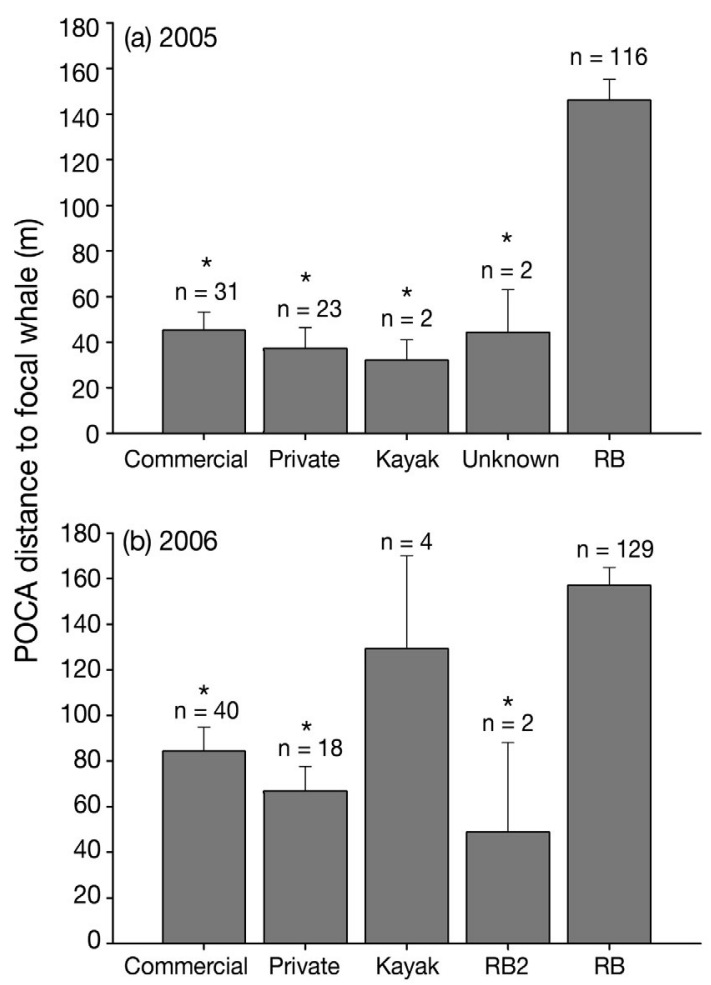

Fig. 1. Point of closest approach (POCA) distances to southern resident killler whales Orcinus orca, characterized by vessel type in (a) 2005 and (b) 2006. Mean POCA distances for commercial, private, kayak, unknown (2005 only), research boat (RB; present study) and other research boat (RB2; conducting non-related study, 2006 only) are presented with +1 SE bars. $\mathrm{n}$ : number of times each vessel type was the vessel with the POCA. *: the POCA distance was significantly less than that of the RB

Table 4. Orcinus orca. Percent occurrence of all surface active behaviors (see Table 1 for details) performed by focal southern resident killer whales

\begin{tabular}{cccccccc} 
Year & Dorsal slap (\%) & Pectoral fin slap (\%) & Tail slap (\%) & Cartwheel (\%) & Breach (\%) & Half breach (\%) & Spyhop (\%) \\
\hline 2005 & 0 & 12 & 66 & 3 & 13 & 0 & 6 \\
2006 & 2 & 7 & 66 & 11 & 7 & 2 & 5 \\
\hline
\end{tabular}


distances from 2005 (median $=25 \mathrm{~m}$, mean $=41.2 \pm$ $5.8 \mathrm{~m})$ to $2006($ median $=85.5 \mathrm{~m}$, mean $=90.0 \pm 7.9 \mathrm{~m})$ was highly significant ( $T=2714.5, \mathrm{p}<0.001$ ) (Fig. 1). Finally, of all POCAs by vessels other than the research vessel, 91 and $65 \%$ were $\leq 100 \mathrm{~m}$ from focal whales in 2005 and 2006, respectively. This result shows that commercial whale-watching and private boats were often within 0 to $100 \mathrm{~m}$ of whales, which contravenes the local voluntary guidelines for watching southern resident killer whales.

The POCA distances by vessel type were significantly distinct (Kruskal-Wallis 1-way ANOVA, 2005: $H=73.6$, df $=4, \mathrm{p}<0.001 ; 2006: H=49.2$, df $=4, \mathrm{p}<$ 0.001) (Fig. 1). Furthermore, POCA distances for the research boat were significantly farther away from focal whales than POCA distances for both commercial whale-watching and private boats in 2005 and 2006 (all p < 0.001) (Fig. 1). The POCA distances for commercial whale-watching and private boats were not discernibly different in either year $(p>0.05)$.

\section{Relationship between killer whale SABs and close approaches by vessels}

The distributions of POCA distances measured during focal follows with SABs differed from those measured during focal follows without SABs in 2005 and 2006 (K-S test, 2005: $D=0.800, \mathrm{p}<0.001 ; 2006: D=$ 0.707, p < 0.001) (Fig. 2). These distributions were best fit by Gumbel distributions. The modes for the estimated distributions of POCA distances measured during focal follows with SABs (2005: $61.6 \mathrm{~m} ;$ 2006: $84.6 \mathrm{~m}$ ) were closer than those meaured during focal follows without SABs (2005: 68.8 m, 2006: 93.9 m). POCA distances for focal follows with SABs also tended to be more narrowly distributed than those without SABs. Seventy-five percent of POCA distances for focal follows with SABs were $\leq 129 \mathrm{~m}$ in 2005 and $\leq 141 \mathrm{~m}$ in 2006 (Fig. 2). In contrast, 75\% of POCA distances for focal follows without SABS were $\leq 139 \mathrm{~m}$ in 2005 and $\leq 163 \mathrm{~m}$ in 2006 (Fig. 2).

The performance of SABs by killer whales tended to be associated with close approaches by vessels (Fig. 3). Distributions of time differentials between the occurrence of the closest approach and the performance of SAB bouts during focal follows were not significantly different between the 2 years (K-S test, $D=0.183, \mathrm{p}=$ $0.356)$, thus the data were combined for analysis. The distribution of time differentials differed significantly from a uniform distribution $(D=0.249, \mathrm{p}<0.0001)$; instead, a normal distribution best fit the data. For both years combined, the distribution did not significantly differ from normal with a mode of -0.5 min and an SD of $6(D=0.109, \mathrm{p}=0.185)$. This implies that the major-

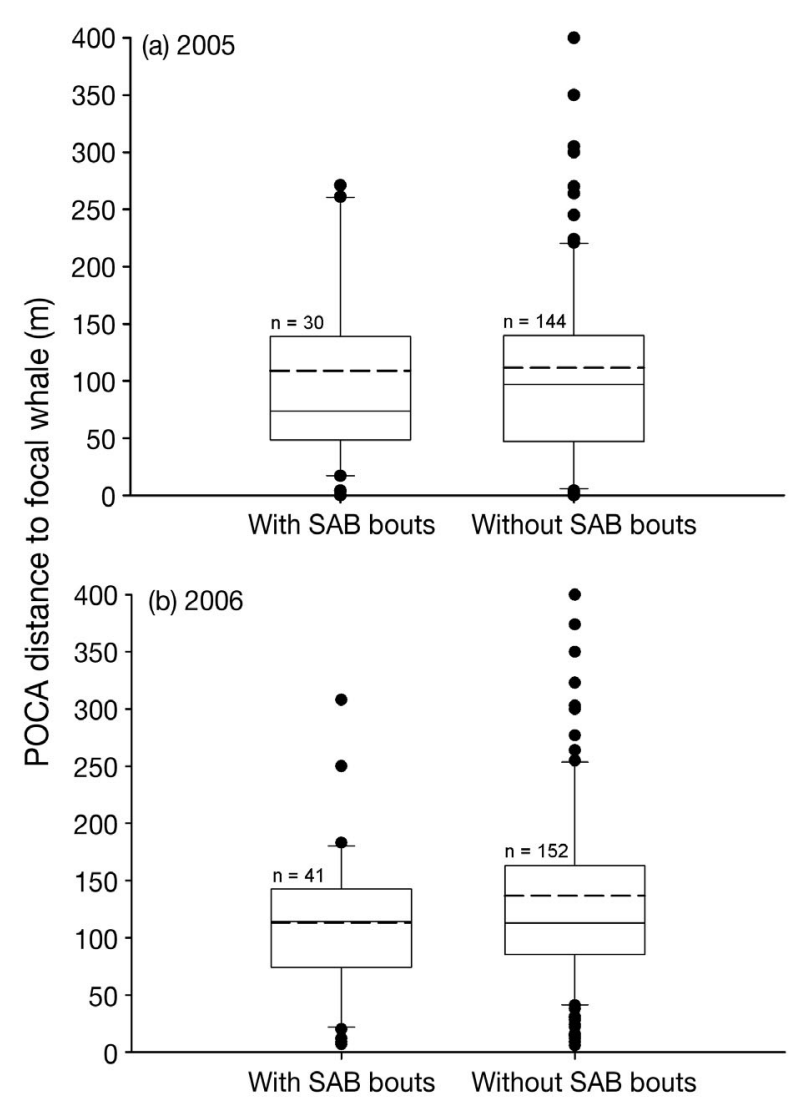

Fig. 2. Orcinus orca. Point of closest approach (POCA) distances during focal follows with and without surface active behavior (SAB) bouts for (a) 2005 and (b) 2006. Box plots are presented with the dashed and solid lines within the boxes representing the mean and median values, respectively. Box boundaries indicate the 25th and 75th percentiles, error bars indicate the 10th and 90th percentiles and all outlying data are designated by filled circles. Numbers indicate the sample size for each box plot

ity of SABs were performed $30 \mathrm{~s}$ after the point of closest approach by a vessel, and that the performance of SABs was more likely to occur near the time of the POCA during a focal follow (Fig. 3). For the 2 years combined, the highest frequency $(21 \%)$ of SAB bouts occurred during and within $2 \mathrm{~min}$ following (time $=0$ to -2$)$ the POCA, and the second highest frequency $(10 \%)$ of SAB bouts occurred within 2 min prior to the POCA. Furthermore, approximately half (46\%) of the 100 total SAB bouts were observed within \pm 4 min of the POCA.

\section{Relationship between killer whale SABs and vessel distance and behavior}

The distributions of distances between the nearest vessel and the focal whale during SAB bouts were best 


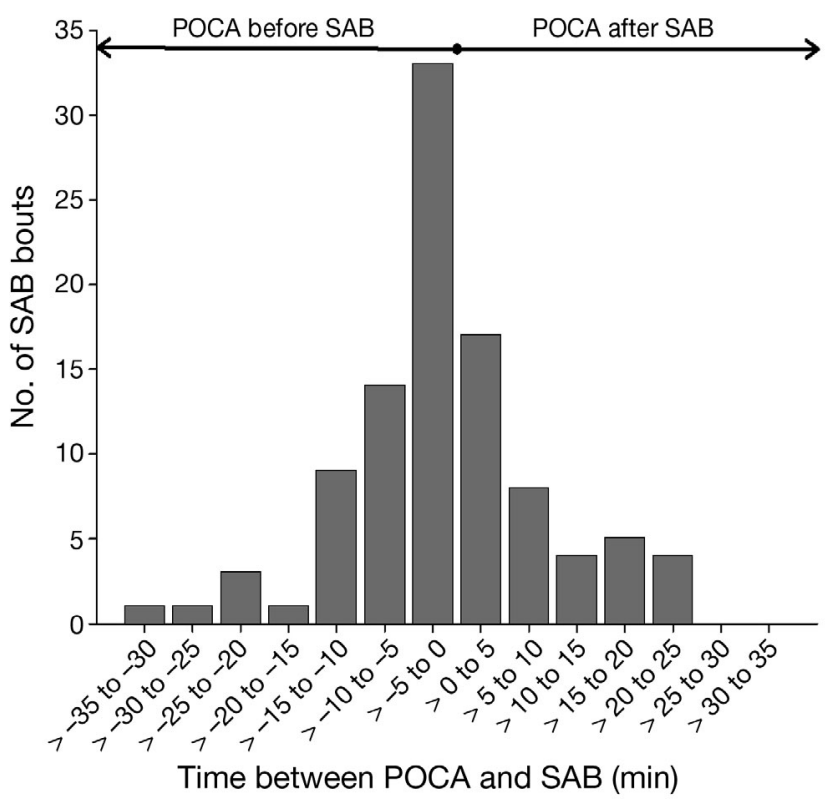

Fig. 3. Orcinus orca. Number of surface active behavior (SAB) bouts in relation to the time elapsed between the occurrence of the point of closest approach (POCA) and the SAB bout (2005 and 2006 data are combined). Time elapsed is presented in 5 min bins. Negative, zero and positive time values indicate POCAs that occurred prior to, simultaneous to and after SAB bouts, respectively

fit by Gumbel distributions, but these distributions differed significantly between the 2 years (K-S test, $D=$ 0.320, $\mathrm{p}=0.011$ ). Similar to data for the POCA, the mode for the estimated distribution of nearest vessel distances during SAB bouts in 2005 (128.0 m) was approximately $25 \mathrm{~m}$ closer than the estimated mode in 2006 (153.2 m).

The majority of SAB bouts were displayed while vessels were relatively close to the focal whale (Fig. 4). For both years, $70 \%$ of SAB bouts occurred when the nearest vessel was within $224 \mathrm{~m}$ of the focal whale. The highest number of SAB bouts occurred when the nearest vessel was between 75 and $99 \mathrm{~m}$ from the focal whale in $2005(27 \%, 11$ of 41 total SAB bouts) and between 125 and $149 \mathrm{~m}$ from the focal whale in $2006(20 \%, 12$ of 59 total SAB bouts) (Fig. 4a,b). Furthermore, in 2006, $70 \%$ of the SAB bouts that were performed at distances of $\leq 149 \mathrm{~m}$ from the nearest vessel occurred while the nearest vessel was motoring (Fig. 4b).

SAB bouts were more likely to occur during focal follows when whales were approached closely. For the purpose of this analysis, the break point between the 2 distance categories ('close' and 'far') for each year is the average POCA (2005: $111.1 \pm 7.4 \mathrm{~m}, 2006: 131.7 \pm$ $6.5 \mathrm{~m}$ ) rounded to the nearest $50 \mathrm{~m}$ because $50 \mathrm{~m}$ distance increments are likely practical for management purposes. In 2005, a significantly higher proportion of

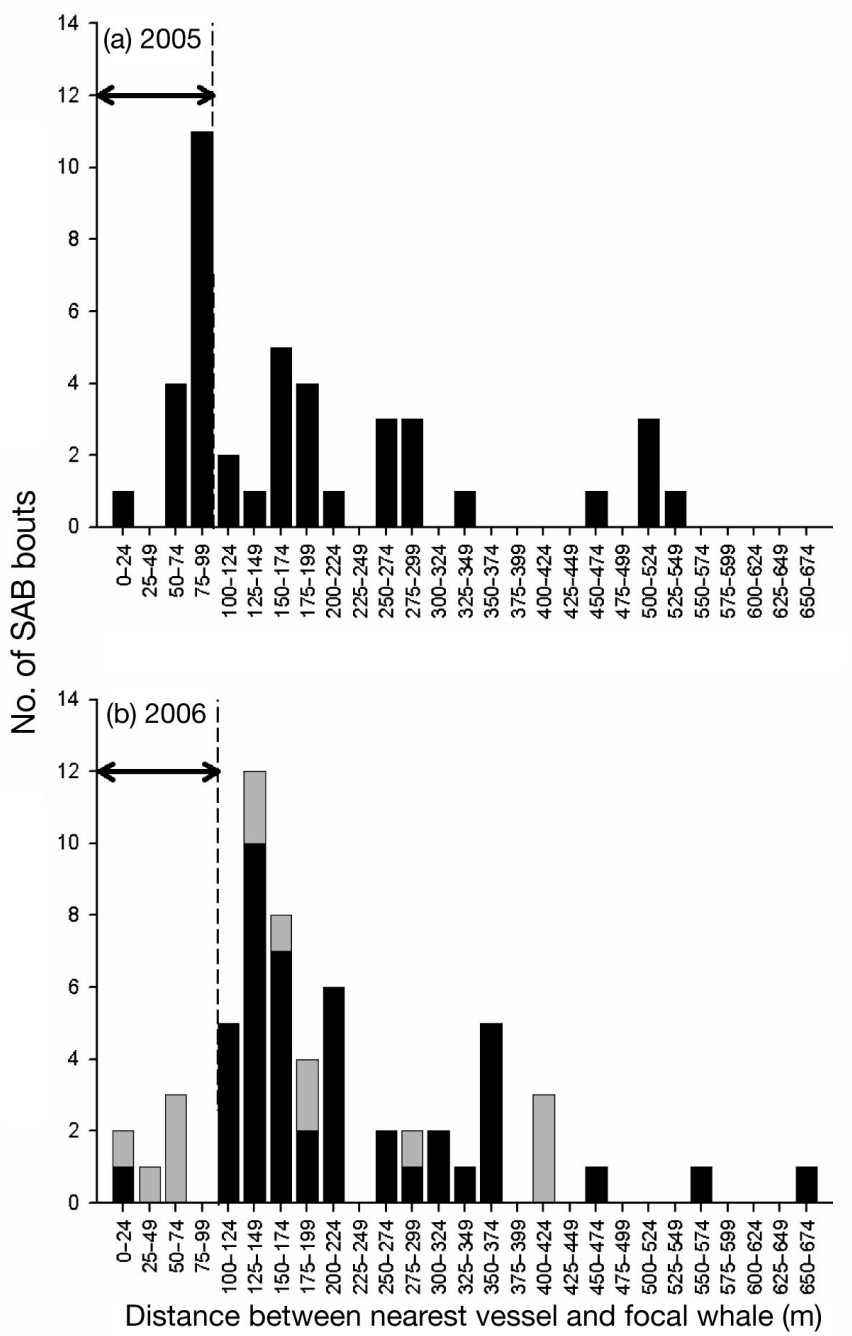

Fig. 4. Orcinus orca. Number of surface active behavior (SAB) bouts in relation to the distance between the focal whale and the nearest vessel during the SAB bout in (a) 2005 and (b) 2006. Distance data are presented in $25 \mathrm{~m}$ bins. In 2006, the $\mathrm{SAB}$ bouts are presented as stacked bars, with motoring vessels designated by black bars and stationary vessels (idling or shut-down) designated by grey bars. The $100 \mathrm{~m}$ 'no go' zone, in which boats are discouraged from approaching southern resident killer whales by guidelines (http://www. bewhalewise.org/bewhalewise.pdf), is shown by the dashed line and double-ended arrow for both years

SAB bouts occurred during focal follows with 'close' (0 to $99 \mathrm{~m})$ compared to 'far' $(\geq 100 \mathrm{~m})$ POCAs $\left(\chi^{2}=5.3, \mathrm{p}=\right.$ 0.02) (Table 5). In 2006, a higher proportion of SAB bouts occurred during focal follows with 'close' (0 to $149 \mathrm{~m}$ ) compared to 'far' ( $\geq 150 \mathrm{~m}$ ) POCAs, though this difference was not significant at the level of $p=0.05$ $\left(\chi^{2}=2.6, p=0.10\right)$ (Table 5). However, the power of the test for the 2006 data was low because of the small sample size for 'far' POCAs. Consequently, the beta probability (probability of accepting a false null hypothesis, Zar 1996) was high ( $\beta=0.65)$, and a sample size 
Table 5. Orcinus orca. Number of focal follows with 'close' and 'far' point of closest approach (POCA) distances during which focal whales did and did not perform surface active behavior (SAB) bouts in 2005 and 2006. Distance bins represent 'close' (2005: 0-99 m, 2006: 0-149 m) and 'far' POCA distances (2005: $\geq 100 \mathrm{~m}, 2006: \geq 150 \mathrm{~m})$

\begin{tabular}{|lcc|}
\hline POCA distance $(\mathrm{m})$ & $\begin{array}{c}\text { No. of focal } \\
\text { follows with } \\
\text { SAB bouts }\end{array}$ & $\begin{array}{c}\text { No. of focal follows } \\
\text { without SAB bouts }\end{array}$ \\
\hline $\mathbf{2 0 0 5}$ & & \\
$0-99$ & 30 & 74 \\
$\geq 100$ & 11 & 70 \\
$\mathbf{2 0 0 6}$ & & 105 \\
$0-149$ & 48 & 47 \\
$\geq 150$ & 11 & \\
\hline
\end{tabular}

of 436 focal follows (316 with POCAs $\leq 149 \mathrm{~m}$ and 120 with POCAs $\geq 150 \mathrm{~m}$ ) is required to conclude that the difference is significant at the level of $p=0.05$ and power $=0.80$.

The number of behaviors within an SAB bout tended to differ with vessel behavior and distance to the whale. In 2006, most SAB bouts consisted of only 1 to 2 SABs, yet SAB bouts consisting of 3 to 8 behaviors were performed when the nearest vessel was motoring. In contrast, only 1 to 2 SABs were performed in bouts when the nearest vessel was stationary (Fig. 5a). However, the proportions of SAB bouts consisting of 1 to 2 and $\geq 3$ behaviors were not significantly different between the 2 vessel operation modes (Fisher's exact test, $\mathrm{p}=0.33$ ). Furthermore, the majority of SAB bouts consisting of $\geq 3$ SABs were performed at 'close' distances (2005: $\leq 100 \mathrm{~m} ; 2006$ : $\leq 149 \mathrm{~m})$, yet, for both 2005 and 2006, the proportion of SAB bouts with $\geq 3$ SABs did not significantly differ between these and greater distances (Fisher's exact test, 2005: $\mathrm{p}=0.36 ; 2006$ : $\mathrm{p}=$ 0.37 ). Still, the sample size of SAB bouts with $\geq 3$ behaviors was small for both years, so additional data are needed to determine if vessel operation mode and distance to the whale are related to the number of SABs performed in a bout. Finally, tail slaps occurred more frequently than any other behavior (Table 4) regardless of whether the nearest vessel was stationary or motoring (Fig. 5b).

\section{DISCUSSION}

The results from the present study demonstrate that southern resident killer whales perform SABs during all activity states. Although killer whales likely perform SABs for several reasons, it is probable that the performance of some is in response to the presence of vessels. The data from the present study and field observations suggest that killer whales may perform
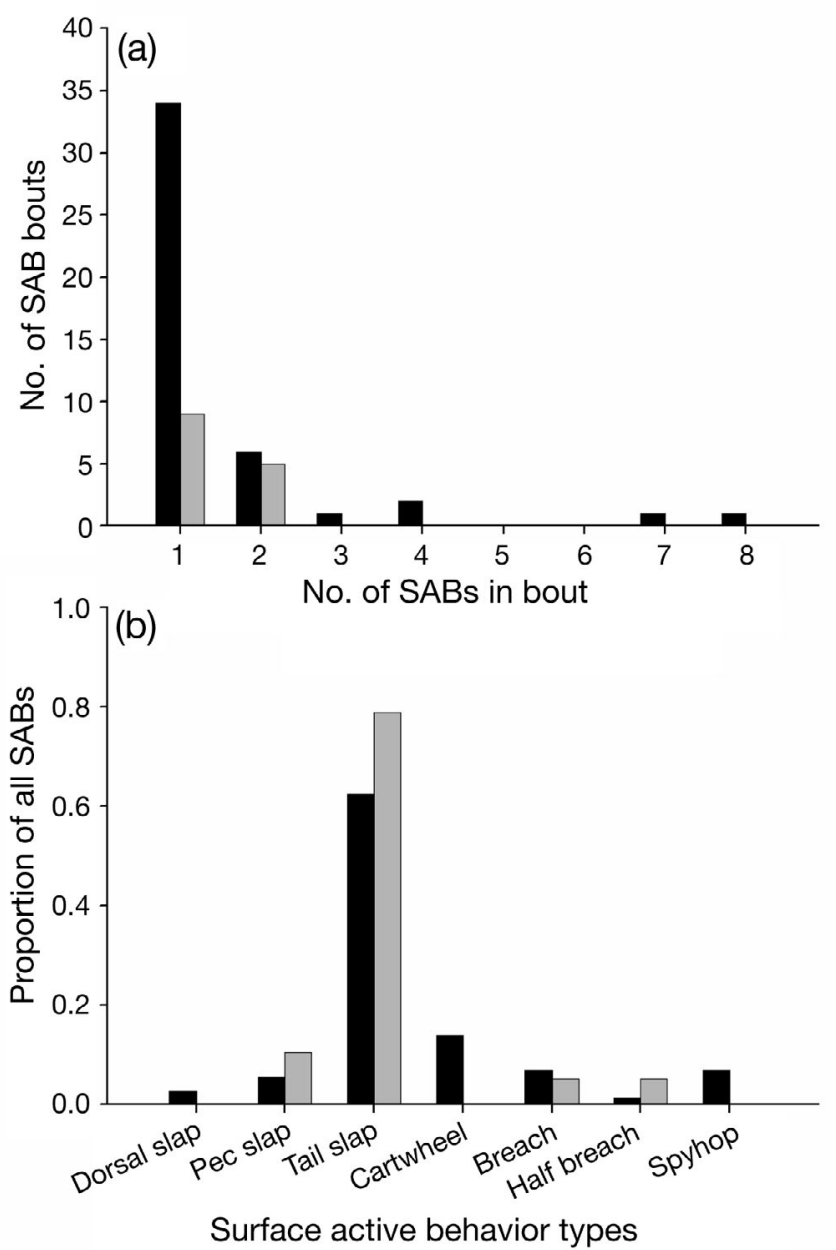

Fig. 5. Orcinus orca. Number of surface active behavior (SAB) bouts performed in 2006 in relation to the number of SABs performed within a bout (a) and the proportion of each $\mathrm{SAB}$ type performed in all SAB bouts (b) when the nearest vessel was motoring (black bars) or stationary (idling or shut-down; grey bars)

SABs in response to close approaches by vessels. Furthermore, these whales may react more often to vessels moving under motor power compared to stationary (idling or shut-down) vessels.

In the present study, killer whales performed SABs during all activity states (rest, forage, travel and social). Because SABs were predominantly performed during travel, which was also the predominant activity state observed, it is likely that activity state was not the only factor influencing the performance of SABs by southern resident killer whales. Indeed, the finding that proportionally more SABs were performed during focal follows with close approaches and the significant temporal relationship between the POCA and the performance of SABs are indicative of killer whales responding to close approaches by vessels, rather than a consequence of collecting data during certain activity states. In previous studies, the performance of SABs by 
killer whales (Duffus \& Baird 1995) and dolphins (Lusseau 2006a) have also been linked to vessel approaches. For example, sideflops were most often observed when powerboats traveled at fast speed and passed within $50 \mathrm{~m}$ of bottlenose dolphins Tursiops sp. (Lusseau 2006a). Williams et al. (2009) also found that SABs were more likely to occur as boats got closer to southern resident killer whales, but the authors did not report the approach distances. Thus, it is not possible to compare the relationships between SABs and POCA distances in the study by Williams et al. (2009) and the present study on southern resident killer whales.

If the voluntary whale-watching guidelines in the area (http://www.bewhalewise.org/bewhalewise.pdf), which suggest vessels avoid approaching southern resident killer whales within $<100 \mathrm{~m}$, were not regularly observed by the whale-watching fleet, the peak frequencies for SAB bouts would likely occur at distances that are closer than we observed. Indeed, the increased distance for the peak frequency of SAB bouts from 2005 to 2006 was most likely attributed to changes in approach distances of private and commercial vessels. This change is evident in the mean POCA distances for the 2 years, particularly for the commercial vessels (Fig. 1). There were a few factors that contributed to this change in behavior. Mainly, in 2006 there was an increased presence of enforcement officials on the water and the guidelines also changed. Vessel operators were expected to move their vessels away from oncoming whales in order to minimize the likelihood that vessels would ever be within $100 \mathrm{~m}$ of whales, even if the whales approached the vessels.

Although several SAB bouts appeared to be linked to close approaches by vessels, SAB bouts also occurred at distances that were quite far from vessels (e.g. >500 m). This demonstrates that SABs are performed during several contexts and thus may serve many purposes. Indeed, surface active behaviors have been linked to feeding (Orcinus orca, Similä \& Ugarte 1993), social (Physeter macrocephalus, Waters \& Whitehead 1990; Orcinus orca, Ford et al. 2000) and sexual and aggressive (Cephalorhynchus hectori, Slooten 1994) behaviors in cetaceans. Several studies have also shown that cetaceans perform SABs in response to disturbance. The performance of SABs are common reactions to biopsy sampling (Weinrich et al. 1992, Clapham \& Mattila 1993, Brown et al. 1994, Gauthier \& Sears 1999, Hooker et al. 2001) and approaches by vessels and swimmers (Weinrich et al. 2001, Williams et al. 2002a,b, Coscarella et al. 2003, Danil et al. 2005, Lusseau 2006a). Similarly, the findings in the present study that more SABs were performed when vessels approached whales closely and that the majority of SAB bouts were performed near the time of the POCA suggest that close approaches and/or changes in vessel behavior or distance may elicit SAB performance in southern resident killer whales.

Likewise, temporal patterns in behavioral changes by bottlenose dolphins have been linked to close approaches by vessels. For example, Buckstaff (2004) found that whistle rates were significantly greater within 1 min prior to vessel approach, followed by a significant decline as vessels passed (Buckstaff 2004). Similarly, Miller et al. (2008) found that several behavioral changes occurred within the first minute following the passing of high-speed personal watercraft within $100 \mathrm{~m}$.

The function of performing SABs will never be known for certain, yet it is feasible that southern resident killer whales perform SABs as a form of communication while in close proximity to vessels. These signals could serve to promote group coordination, warn conspecifics of a vessel's presence or alert vessels to the whales' presence. Because SABs provide a visual as well as an acoustic cue, these behaviors may aid killer whale communication when ambient noise is elevated, as is the case when several vessels are present (Holt et al. 2009). The observations that SAB bouts tended to consist of more SABs when the nearest vessel was motoring and when vessels were very close provides additional evidence to support the hypothesis that SABs can be performed in response to vessel disturbance. Williams et al. (2002a) also found that male northern resident killer whales tended to increase rates of SABs in response to leapfrogging vessels. Similarly, dolphins increased the number of whistles produced in response to transiting vessels (Van Parijs \& Corkeron 2001, Buckstaff 2004).

Southern resident killer whales tended to perform tail slaps more often than other SABs. Tail slaps allow for both visual and acoustic communication and may be performed by killer whales when disturbed (Ford et al. 2000). This preference for performing tail slaps is similar to the northern resident killer whale population (Williams et al. 2002a,b), whose male members tend to increase rates of SABs as the number of whaleoriented vessels increase (Williams et al. 2002b). Similarly, spinner dolphins were observed to repeatedly tail slap near swimmers and kayakers that were following the group (Courbis \& Timmel 2009). These behaviors may carry motivational or intentional information (Lusseau 2006b). Individuals may be able to transfer information non-vocally about the direction to take (Lusseau 2006b), or designate the location of a vessel (present study), by attracting the attention of others that can observe the direction and location of the tail slapping animal (Lusseau 2006b). The use of this particular behavior is likely a cost-effective method for combined visual and acoustic communication in killer whales. Although most surface active behaviors are 
easily seen and heard, tail slaps are far less energetically expensive to perform than breaches (Waters \& Whitehead 1990, D. Noren unpubl. data). Indeed, visual displays involving tail movements are commonly used by organisms across several taxa to deter predators and/or potentially alarm conspecifics (Hersek \& Owings 1993, 1994, Brown et al. 1999, Cooper 2001, Langkilde et al. 2004, Alvarez et al. 2006, Murphy 2007).

While there are several variables that likely determine whether vessel presence will elicit a response, it was not feasible to address them all in the present study. The performance of SABs was relatively rare ( $20 \%$ of all focal follows conducted in 2005 and 2006) and thus it is clear that these whales do not always respond to vessels by performing these behaviors. However, the results from the present study suggest that a significant portion (approximately $50 \%$ ) of SAB bouts that were performed by southern resident killer whales may be related to vessel distance and behavior. Reactions may be more likely to occur under particular conditions, such as when vessels approach whales at exceptionally close distances or when there are several boats nearby simultaneously operating in potentially harmful modes. Unfortunately, due to the high level of traffic and diversity of vessel types in the area, it was not possible to include additional vessel characteristics (e.g. size, motor type, trajectory) in the analysis.

The performance of SABs is likely to have a relatively minor energetic impact compared to other previously documented responses of resident killer whales to vessels. This is because these behaviors do not constitute a substantial portion of southern resident killer whales' daily energy budgets due to the rarity of their occurrence and the preferential performance of tail slaps over other SABs. As mentioned previously, tail slaps have a relatively low energetic cost (D. Noren unpubl. data). Instead, decreased energy consumption in response to vessel traffic may be of greater concern for resident killer whales. Previous studies on northern (Williams et al. 2006) and southern (Lusseau et al. 2009) resident killer whales have found that whales spend less time feeding and more time traveling while in the presence of vessels. These activity budget changes were estimated to increase energy demand by approximately $3 \%$ while they more substantially decrease energy gain by approximately $28 \%$ in northern resident killer whales (Williams et al. 2006). Thus, increased energy expenditure by either increasing travel (Williams et al. 2006, Lusseau et al. 2009) or increasing SAB rates (Williams et al. 2002a,b, present study) is expected to have a relatively minimal energetic impact compared to reduced prey acquisition (Williams et al. 2006, Lusseau et al. 2009) in response to vessels.
However, because food resources of southern resident killer whales may be limited (Ford et al. 2005), vessel guidelines that minimize impacts which increase energy expenditure and/or decrease energy acquisition will likely be important to the recovery of this population. Indeed, without the voluntary guidelines, it is possible that the number of very close approaches $(<100 \mathrm{~m})$ by vessels would have been greater than what was observed during the present study. If the linkage between the performance of some SABs and close approaches is valid, then it is likely that $\mathrm{SAB}$ rates could increase if the number of close approaches by vessels increases. This increase in SAB rate may potentially increase the daily energy expenditure of killer whales. Thus, guidelines that prohibit close approaches by vessels could be important in reducing the energetic impacts of vessel disturbance.

The results from the present study and future research could be used to update and modify the voluntary guidelines and/or inform decisions on regulations for vessels in the vicinity of southern resident killer whales. The existing voluntary guidelines request that vessels do not approach whales within a $100 \mathrm{~m}$ radius and that they slow down to $<7$ knots within a $400 \mathrm{~m}$ radius. However, results from the present study as well as previous studies on killer whales (Erbe 2002, Williams et al. 2002a,b, 2006, Williams \& Ashe 2007) and dolphins (Van Parijs \& Corkeron 2001, Kreb \& Rahadi 2004) demonstrate that vessels can affect cetacean behavior at distances $\geq 100 \mathrm{~m}$. Furthermore, motoring vessels, even when transiting well beyond $100 \mathrm{~m}$ from cetaceans, can cause behavioral impacts (Van Parijs \& Corkeron 2001, Erbe 2002, Goodwin \& Cotton 2004, Kreb \& Rahadi 2004, present study). Thus, it appears that the current guidelines may not adequately prevent southern resident killer whale behavioral responses to vessels. Furthermore, data from the present study also demonstrate that vessels routinely violated the current $100 \mathrm{~m}$ 'no-go zone'. At the very minimum, increasing the minimum approach distance to $>100 \mathrm{~m}$ will provide the whales with a larger buffer zone from boats. This would thereby reduce the number of vessels that approach killer whales within $\leq 100 \mathrm{~m}$, thus reducing acoustic impacts (Erbe 2002) and behavioral responses (Erbe 2002, Williams et al. 2002a,b, present study).

Finally, minimizing disturbance is important because short-term behavioral responses to disturbance from whale-watching can have long-term consequences for individuals and populations (Lusseau \& Bejder 2007). Furthermore, species that do not avoid disturbance may be most adversely affected by it (Gill et al. 2001). For example, southern resident killer whales stay in the area of disturbance because they consume mobile and highly aggregated prey that are localized in the 
San Juan Island region during the summer, and are thus forced to tolerate disturbance, which may impact their population (Gill et al. 2001). Because of this, it is particularly critical to fully understand and minimize the cumulative effects of vessel disturbance and other anthropogenic impacts on this endangered population.

Acknowledgements. We thank Snug Harbor Resort, The University of Washington (UW) Friday Harbor Laboratories, Orca Network, Soundwatch, the commercial whale-watching fleet, and Drs. J. Ha and J. Marsh from the Department of Psychology, UW, for field support. We are grateful to J. Mocklin and J. Daly for safely operating the research vessel in the vicinity of killer whales, and we thank E. Beardsley, E. Ashe, and D. Giles for data collection and assistance in the field. D. Rehder was funded through the NOAA Ernest F. Hollings Undergraduate Scholarship Program. Drs. M. Ford, B. Hanson, and M. Holt and L. Barre provided constructive comments on previous drafts of this manuscript. This work was funded by the NOAA Fisheries Northwest Fisheries Science Center. In 2005, the research was conducted by the authority of the US Marine Mammal Protection Act General Authorization no. 781-172501, Canadian Marine Mammal License (MML) no. 2005-003, and Species at Risk Act (SARA) permit no. 10. In 2006, the research was conducted by the authority of the US Endangered Species Act permit no. 781-1824-00, Canadian MML no. 2006-07, and SARA permit no. 33.

\section{LITERATURE CITED}

Allen MC, Read AJ (2000) Habitat selection of foraging bottlenose dolphins in relation to boat density near Clearwater, Florida. Mar Mamm Sci 16:815-824

Alvarez F, Sánchez C, Angulo S (2006) Relationships between tail-flicking, morphology, and body condition in moorhens. J Field Ornithol 77:1-6

Au WWL, Green M (2000) Acoustic interaction of humpback whales and whale-watching boats. Mar Environ Res 49: 469-481

Au D, Perryman W (1982) Movement and speed of dolphin schools responding to an approaching ship. Fish Bull 80: 371-379

Bejder L, Dawson SM, Harraway JA (1999) Responses by Hector's dolphins to boats and swimmers in Porpoise Bay, New Zealand. Mar Mamm Sci 15:738-750

Bejder L, Samuels A, Whitehead H, Gales N (2006) Interpreting short-term behavioural responses to disturbance within a longitudinal perspective. Anim Behav 72: 1149-1158

Bigg M (1982) An assessment of killer whale (Orcinus orca) stocks off Vancouver Island, British Columbia. Rep Int Whal Comm 32:655-666

Brown MR, Corkeron PJ, Hale PT, Schultz KW, Bryden MM (1994) Behavioral responses of East Australian humpback whales Megaptera novaeangliae to biopsy sampling. Mar Mamm Sci 10:391-400

Brown GE, Godin JGJ, Pedersen J (1999) Fin-flicking behavior: a visual antipredator alarm signal in a characin fish, Hemigrammus erythrozonus. Anim Behav 58:469-475

Buckstaff KC (2004) Effects of watercraft noise on the acoustic behavior of bottlenose dolphins, Tursiops truncatus, in Sarasota Bay, Florida. Mar Mamm Sci 20:709-725

Chilvers BL, Corkeron PJ, Puotinen ML (2003) Influence of trawling on the behaviour and spatial distribution of Indo-
Pacific bottlenose dolphins (Tursiops aduncus) in Moreton Bay, Australia. Can J Zool 81:1947-1955

Clapham PJ, Mattila DK (1993) Reactions of humpback whales to skin biopsy sampling on a West Indies breeding ground. Mar Mamm Sci 9:382-391

Constantine R, Brunton DH, Dennis T (2004) Dolphinwatching tour boats change bottlenose dolphin (Tursiops truncatus) behaviour. Biol Conserv 117:299-307

> Cooper WE (2001) Multiple roles of tail display by the curlytailed lizard Leiocephalus carinatus: pursuit deterrent and deflective roles of a social signal. Ethology 107:1137-1149

Corkeron PJ (2004) Whale watching, iconography, and marine conservation. Conserv Biol 18:847-849

Coscarella MA, Dans SL, Crespo EA, Pedraza SN (2003) Potential impact of unregulated dolphin watching activities in Patagonia. J Cetacean Res Manag 5:77-84

Courbis S, Timmel G (2009) Effects of vessels and swimmers on behavior of Hawaiian spinner dolphins (Stenella longirostris) in Kealake'akua, Honaunau, and Kauhako bays, Hawai'i. Mar Mamm Sci 25:430-440

> Danil K, Maldini D, Marten K (2005) Patterns of use of Maku'a Beach, O'ahu, Hawai'i, by spinner dolphins (Stenella longirostris) and potential effects of swimmers on their behavior. Aquat Mamm 31:403-412

Duffus DA, Baird RW (1995) Killer whales, whalewatching, and management: a status report. Whalewatcher 29:14-17

Ellifrit DK, Balcomb KC, van Ginneken AM (2006) Official orca survey photo identification guide to orca whales of the Southern Resident community, spring 2006 edn. Center for Whale Research, Friday Harbor, WA

> Erbe C (2002) Underwater noise of whale-watching boats and potential effects on killer whales (Orcinus orca), based on an acoustic impact model. Mar Mamm Sci 18:394-418

Foote AD, Osborne RW, Hoelzel AR (2004) Whale-call response to masking boat noise. Nature 428:910

Ford JKB (1989) Acoustic behaviour of resident killer whales (Orcinus orca) off Vancouver Island, British Columbia. Can J Zool 67:727-745

Ford JKB, Ellis GM, Balcomb KC (2000) Killer whales, 2nd edn. UBC Press, Vancouver, BC

Ford JKB, Ellis GM, Olesiuk PF (2005) Linking prey and population dynamics: Did food limitation cause recent declines of 'resident' killer whales (Orcinus orca) in British Columbia? Canadian Science Advisory Secretariat Research Document 2005/042, available at: www.dfompo.gc.ca/csas/Csas/Publications/ResDocsDocRech/2005/2005_042_e.htm

Gauthier J, Sears R (1999) Behavioral response of four species of balaenopterid whales to biopsy sampling. Mar Mamm Sci 15:85-101

Gill JA, Norris K, Sutherland WJ (2001) Why behavioral responses may not reflect the population consequences of human disturbance. Biol Conserv 97:265-268

Goodwin L, Cotton PA (2004) Effects of boat traffic on the behaviour of bottlenose dolphins (Tursiops truncatus). Aquat Mamm 30:279-283

> Hersek MJ, Owings DH (1993) Tail flagging by adult California ground squirrels: a tonic signal that serves different functions for males and females. Anim Behav 46:129-138

Hersek MJ, Owings DH (1994) Tail flagging by young California ground squirrels, Spermophilus beecheyi: agespecific participation in a tonic communicative system. Anim Behav 48:803-811

> Hodgson AJ, Marsh H (2007) Response of dugongs to boat traffic: the risk of disturbance and displacement. J Exp Mar Biol Ecol 340:50-61

Holt MM, Noren DP, Veirs V, Emmons C, Veirs S (2009) 
Speaking up: killer whales (Orcinus orca) increase their call amplitude in response to vessel noise. J Acoust Soc Am 125:EL27-EL32

Hooker SK, Baird RW, Al-Omari S, Gowans S, Whitehead H (2001) Behavioral reactions of northern bottlenose whales (Hyperoodon ampullatus) to biopsy darting and tag attachment procedures. Fish Bull 99:303-308

Jahoda M, Lafortuna CL, Biassoni N, Almirante C and others (2003) Mediterranean fin whale's (Balaenoptera physalus) response to small vessels and biopsy sampling assessed through passive tracking and timing of respiration. Mar Mamm Sci 19:96-110

Janik VM, Thompson PM (1996) Changes in surfacing patterns of bottlenose dolphins in response to boat traffic. Mar Mamm Sci 12:597-602

> Jelinski DE, Krueger CC, Duffus DA (2002) Geostatistical analyses of interactions between killer whales (Orcinus orca) and recreational whale-watching boats. Appl Geogr 22:393-411

King JM, Heinen JT (2004) An assessment of the behaviours of overwintering manatees as influenced by interactions with tourists at two sites in central Florida. Biol Conserv $117: 227-234$

Koski KL (2004) 1998-2003 Final Program Report: Soundwatch Public Outreach/Boater Education Project. Contract No. AB133F-03-SE-1126. The Whale Museum, Friday Harbor, WA

Koski KL (2006) 2004-2005 Final Program Report: Soundwatch Public Outreach/Boater Education Project. Contract No. AB133F-04-SE-0835. The Whale Museum, Friday Harbor, WA

Koski KL (2007) 2006 Final Program Report: Soundwatch Public Outreach/Boater Education Project. Contract No. AB133F-04-SE-0653. The Whale Museum, Friday Harbor, WA

Krahn MM, Wade PR, Kalinowski ST, Dahlheim ME and others (2002) Status review of southern resident killer whales (Orcinus orca) under the Endangered Species Act. US Dept of Commerce NOAA Tech Memo NMFS-NWFSC-54

Kreb D, Rahadi KD (2004) Living under an aquatic freeway: effects of boats on Irrawaddy dolphins (Orcaella brevirostris) in a coastal and riverine environment in Indonesia. Aquat Mamm 30:363-375

Kruse S (1991) The interactions between killer whales and boats in Johnstone Strait, B.C. In: Pryor K, Norris KS (eds) Dolphin societies: discoveries and puzzles. University of California Press, Berkeley, CA, p 149-159

Langkilde T, Schwarzkopf L, Alford RA (2004) The function of tail displays in male rainbow skinks (Carlia jarnoldae). J Herpetol 37:328-335

> Lemon M, Lynch TP, Cato DH, Harcourt RG (2006) Response of travelling bottlenose dolphins (Tursiops aduncus) to experimental approaches by a powerboat in Jervis Bay, New South Wales, Australia. Biol Conserv 127:363-372

Luck M (2003) Education on marine mammal tours as agent for conservation - but do tourists want to be educated? Ocean Coast Manag 46:943-956

Lusseau D (2003a) Effects of tour boats on the behavior of bottlenose dolphins: using Markov chains to model anthropogenic impacts. Conserv Biol 17:1785-1793

Lusseau D (2003b) Male and female bottlenose dolphins Tursiops spp. have different strategies to avoid interactions with tour boats in Doubtful Sound, New Zealand. Mar Ecol Prog Ser 257:267-274

Lusseau D (2004) The hidden cost of tourism: detecting longterm effects of tourism using behavioral information. Ecol Soc 9:2
Lusseau D (2005) Residency pattern of bottlenose dolphins Tursiops spp. in Milford Sound, New Zealand, is related to boat traffic. Mar Ecol Prog Ser 295:265-272

Lusseau D (2006a) The short-term behavioral reactions of bottlenose dolphins to interactions with boats in Doubtful Sound, New Zealand. Mar Mamm Sci 22:802-818

> Lusseau D (2006b) Why do dolphins jump? Interpreting the behavioural repertoire of bottlenose dolphins (Tursiops sp.) in Doubtful Sound, New Zealand. Behav Process 73:257-265

Lusseau D, Bejder L (2007) The long-term consequences of short-term responses to disturbance experiences from whalewatching impact assessment. Int J Comp Psychol 20:228-236

> Lusseau D, Bain DE, Williams R, Smith JC (2009) Vessel traffic disrupts the foraging behavior of southern resident killer whales Orcinus orca. Endang Species Res 6:211-221

Marsh JA (2008) Social behavior and ecology of 'Southern Resident' killer whales (Orcinus orca). PhD dissertation, University of Washington, Seattle, WA

Miller LJ, Solangi M, Kuczaj II SA (2008) Immediate response of Atlantic bottlenose dolphins to high-speed personal watercraft in the Mississippi Sound. J Mar Biol Assoc UK 88:1139-1143

Murphy TG (2007) Dishonest 'preemptive' pursuit-deterrent signal? Why the turquoise-browed motmot wags its tail before feeding nestlings. Anim Behav 73:965-970

Ng SL, Leung S (2003) Behavioral response of Indo-Pacific humpback dolphin (Sousa chinensis) to vessel traffic. Mar Environ Res 56:555-567

> Nowacek SM, Wells RS, Solow AR (2001) Short-term effects of boat traffic on bottlenose dolphins, Tursiops truncatus, in Sarasota Bay, Florida. Mar Mamm Sci 17:673-688

> Orams MB (2000) Tourists getting close to whales, is it what whale-watching is all about? Tourism Manag 21:561-569

> Romano TA, Keogh MJ, Kelly C, Feng P and others (2004) Anthropogenic sound and marine mammal health: measures of the nervous and immune systems before and after intense sound exposure. Can J Fish Aquat Sci 61: 1124-1134

Similä T, Ugarte F (1993) Surface and underwater observations of cooperatively feeding killer whales in northern Norway. Can J Zool 71:1494-1499

> Slooten E (1994) Behavior of Hector's dolphin: classifying behavior by sequence analysis. J Mammal 75:956-964

Suryan RM, Harvey JT (1999) Variability in reactions of Pacific harbor seals, Phoca vitulina richardsi, to disturbance. Fish Bull 97:332-339

van Ginneken AM, Ellifrit DK, Balcomb KC (2005) Official orca survey photo identification guide to orca whales of the Southern Resident community, spring 2005 edn. Center for Whale Research, Friday Harbor, WA

- Van Parijs SM, Corkeron PJ (2001) Boat traffic affects the acoustic behaviour of Pacific humpback dolphins, Sousa chinensis. J Mar Biol Assoc UK 81:533-538

- Waters S, Whitehead H (1990) Aerial behaviour in sperm whales. Can J Zool 68:2076-2082

> Weinrich MT, Schilling MR, Belt CR (1992) Evidence for acquisition of a novel feeding behaviour: lobtail feeding in humpback whales, Megaptera novaeangliae. Anim Behav 44:1059-1072

> Weinrich MT, Belt CR, Moren D (2001) Behavior and ecology of the Atlantic white-sided dolphin (Lagenorhynchus acutus) in coastal New England waters. Mar Mamm Sci 17:231-248

Williams R, Ashe E (2007) Killer whale evasive tactics vary with boat number. J Zool 272:390-397

Williams R, Bain DE, Ford JKB, Trites AW (2002a) Behavioural 
responses of male killer whales to a 'leapfrogging' vessel. J Cetacean Res Manag 4:305-310

Williams R, Trites AW, Bain DE (2002b) Behavioural responses of killer whales (Orcinus orca) to whale-watching boats: opportunistic observations and experimental approaches. J Zool 256:255-270

Williams R, Lusseau D, Hammond PS (2006) Estimating relative energetic costs of human disturbance to killer whales (Orcinus orca). Biol Conserv 133:301-311

Editorial responsibility: Sascha Hooker, St. Andrews, UK
Williams R, Bain DE, Smith JC, Lusseau D (2009) Effects of vessels on behaviour patterns of individual southern resident killer whales Orcinus orca. Endang Species Res 6: 199-209

Yazdi P, Kilian A, Culik BM (1999) Energy expenditure of swimming bottlenose dolphins (Tursiops truncatus). Mar Biol 134:601-607

Zar JH (1996) Biostatistical analysis, 3rd edn. Prentice-Hall, Upper Saddle River, NJ

Submitted: May 22, 2008; Accepted: April 7, 2009

Proofs received from author(s): July 3, 2009 